It is impossible to estimate all such savings with precision. In so far as an estimate can be made, the total sum saved is put at $£ 7$ million a year for a scheme covering all eligible children, and at $£ 3$ million for a scheme covering all eligible children except the first in each family. These same figures are used whether the benefits are to be available for all parents or confined to a particular class. It follows that for a universal scheme, covering all parents, the estimated net cost under existing conditions to provide a flatrate allowance of 5s. for every child less than fifteen years old, or over that age if still receiving full-time education, would be $£ 125$ million a year; and to provide allowances for all except the first eligible child in each family the net cost would be $£ 55$ million a year. The corresponding figures for a scheme confined in the main to the classes in the population which are already subject to compulsory national insurance would be $£ 117$ million and $£ 52$ million.

It would be unfortunate if we missed this opportunity of introducing a long-overdue reform. It might be well to start modestly with a scheme covering every eligible child except the first in each family, but to make it universally applicable since, if we can accept the above figures as reasonably accurate, the difference in cost between the universal and the limited scheme is relatively so slight. This would be of help to all except the smallest families. Eugenists would like also to give additional encouragement to families with the best heredity, but to discover the 'best' in this sense and to define it for administrative purposes would be difficult.

\section{RECENT WORK ON GERMINATION}

$\mathrm{O}$ PENING a discussion on seed germination held at the Linnean Society on May 14, Dr. M. A. H. Tincker, of the Royal Horticultural Society's Gardens, Wisley, read a paper dealing with the physiology of germination and incorporating some hitherto unpublished data of germination studies made at Wisley. The importance of low-temperature storage with low relative humidity tested in the United States was illustrated by common vegetable seeds including onion, carrot, leok and tomato. The response of seeds or achenes to various 'stratification' periods and temperatures so fully worked out at the Boyce Thompson Institute was also brought under review. With a number of lilies the seedling roots may grow but the shoots of certain species frequently do not appear for a year or more; while a higher temperature favours root growth, the dormancy of the epicotyl may be terminated by exposure to lower temperatures for a month or two. The seeds of further species of Primula have been shown to be light sensitive. Vernalization studies made at the Imperial College, in which very small embryos may grow into large plants almost as rapidly as normal grain, have an important bearing upon the question of small and large seed. The conditions favourable to the growth of small embryos in Fraxinus were mentioned, as was the widely different behaviour of the acorns of different oak species in regard to their after-ripening requirements in contrast to their similarity in respiration during winter. The interesting artificial methods used in Java of division of young, valuable seedlings of rubber at an early stage of germination to give a greater number of plants were described.
Mr. T. Hay referred to the germination of Emmenanthe (whispering bells) in soil which has been heated. Romneya coulteri also germinated better in heated soil. He stated that Grevillea robusta seed when placed in soil edgewise gave a higher germination than when flat. He mentioned the great difficulty experienced in raising many Cypripediums and the failure of imported seed. Referring to temperature conditions he cited Nemesia as germinating better at low temperatures despite its origin, and in regard to age and maturity preferred two-year-old leek seed and stated that old seed of stocks gave a higher proportion of doubles. He concluded by recounting the interesting story of the re-introduction of Lathyrus magellanicus by seed.

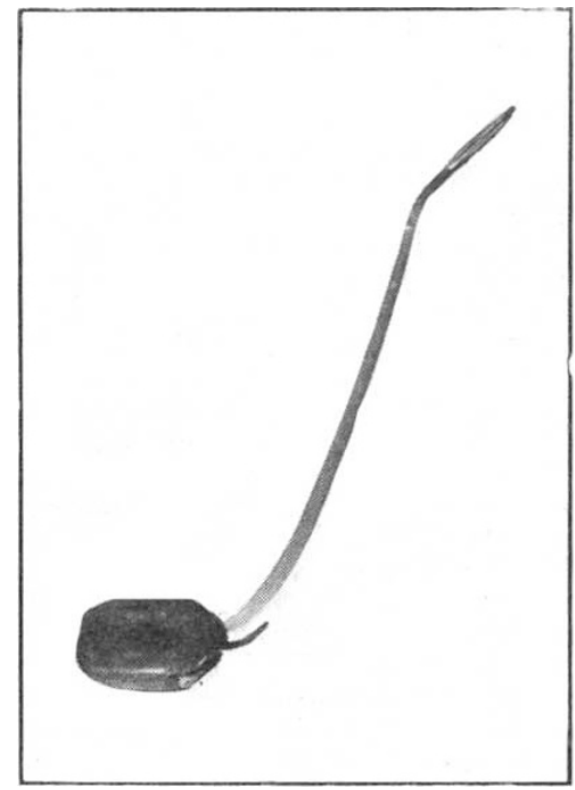

NeluMbium from the SLOANE COLlection Placed in water, after removal of seed-coat, at 5 p.m. on May 12,1942 . Temp. $32^{\circ} \mathrm{C}$. At 2 p.m. on May 13, lin. long. Kept at room temperature aft 3 rwaris and photographed on May 17 , at 10 a.m.

Mr. G. W. Robinson remarked upon the slow germination of Hellebore seed often after 3-4 years from date of sowing, and commented on the Primulas, some of which proved troublesome. High temperatures in bush fires, well known to cause germination in Acacia spp., were observed in South America by him to cause Sisyrinchium striatum to germinate readily. Seed some eighty years old of Cytisus, Melilotus and other species had been successfully germinated.

Dr. J. Ramsbottom exhibited seedlings of Albizzia Julibrissin and Nelumbium. The seeds of the Albizzia were collected during Sir George Staunton's mission to China in 1793 and then stored in the Department of Botany at the British Museum. Following the fire in the Department at South Kensington due to an air raid in September 1940, the seeds became damp and when they were examined in November, were found to have germinated. Three of the seedlings were planted, and grown on at Chelsea Physic Garden ; only one, however, survived the air attacks of May 194l. The main interest is that the seeds germinated 'spontaneously' after their 147 years storage.

Three Nelumbium seedlings were shown. Two of 
these were grown from fruits ('seeds') found in the prehistoric peat bed in the Pulantien Basin, South Manchuria: they are "probably at least three or four hundred years old". The seeds were presented to the Museum by Prof. I. Ohga in 1926; at that time in his experiments they showed a very high percentage of germination. The seeds, after the removal of their seed coats, germinated in water at $32^{\circ} \mathrm{C}$, , one after twenty-one hours, the other by the following morning. The third seedling was grown from a 'seed' taken from a receptacle in the Sloane collections. Robert Brown during 1843-I855 succeeded in obtaining twelve seedlings from fourteen of these seeds. As they were then not less than 150 years old this has stood as the record for longevity of seeds of known origin : Ohga tried twelve seeds in 1926 but none germinated though one seed, on being opened, showed green cotyledons. Only one seed was tried and within twenty-one hours it produced an outgrowth half an inch in length which had increased to more than an inch before the end of the second day. The Sloane Catalogue cannot be consulted conveniently at present so no exact data are available, but eighty-seven years have elapsed since the last of Robert Brown's elassical experiments. The most surprising fact about the germination is the immediate rapid and rampant growth after a dormancy of centuries.

Mr. C. P. Raffill dealt with difficulties experienced in seed importation, stating that only 10 per cent of the seed importations into Kew gave satisfactory germination. $\mathrm{H}_{\theta}$ had experienced the greatest difficulty with seeds from Malaya, South America, East Australia, and East and West Africa and Ceylon. Magnolia seed from China and the Himalayan region failed when imported dry, but when kept moist by moss some germination was obtained. The seed of Michelia and related plants proved short-lived. Many plants from New Zealand (including Araliaceæ) produced seed which apparently died on drying; seed of Nothofagus also was imported successfully in damp storage but unsuccessfully when dried. Reference was made to the small degree of success obtained with the seeds of many tropical fruits.

In a brief reply Dr. M. A. H. Tincker referred to the availability of rapid means of transport by air and of modern methods of temperature control which should be tested for seed importation.

\section{ELECTRICITY OF CLOUD AND RAIN}

\section{BY DR. J. ALAN CHALMERS \\ University of Durham}

$I^{\mathrm{N}}$ his recent presidential address to the Royal Meteorological Society, under the above title, Sir George Simpson ${ }^{1}$ has given a full account of experimental results on the processes giving rise to electrical charges on raindrops and in clouds. Due largely to work in which Sir George has himself taken a big part, a fairly clear picture is now available of the electrical structure of a thunder-cloud, showing a positive charge above and a negative charge below, with a localized concentration of positive charge at a still lower level. There must be two processes of separation of charge : an upper on $\theta$, in a region wher the temperature is below freezing-point, and where the separation has been ascribed by Simpson and Scrase $^{2}$ to a process of friction between ice-particles, giving a negative charge to the larger particles and a positive charge to the air ; and a lower one, where the precipitation is entirely in liquid form, and where the separation of charge is ascribed to the breaking of drops, giving positive drops and a negative charge to the air.

But, as Sir George Simpson points out, the electrical phenomena associated with continuous rain, such as that preceding a warm front, are by no means so clearly understood. Although the meteorological conditions are probably less complex than in a thunder-cloud, the electrical manifestations are much less intense ; and technique, such as that of the altielectrograph, which is available for the investigation of thunder-clouds, is not sufficiently sensitive for the purpose of investigating clouds of the nimbo-stratus type responsible for continuous rain.

The investigation of electrical phenomena due to continuous rain clouds has been mainly confined to the measurement of the charges on the rain and of the vertical potential gradient at the earth's surface. It has been generally found that the charge on the rain is predominantly positive, while the potential gradient is usually negative; the correlation between the two has been established in the case of long. continued gentle rain, in a record analysed by Chalmers and Little $^{3}$ and in records mentioned by Simpson ${ }^{1}$.

The problem of the electricity in continuous rain and the clouds responsible for it amounts to the discussion of the production of positively charged rain and a negative potential gradient. The negative potential gradient must be due to a negative charge situated in the base of the cloud or below it.

\section{Electrical Processes at Work}

The fundamental problem in regard to the electricity of continuous rain is one which can be stated in a number of different forms, now seen to be equivalent. In its simplest form it is as set out by Simpson ${ }^{2}$, namely, the question as to how the rain gets its positive charge. There are two known processes by which water drops could obtain a positive charge under conditions of the kind under discussion : there is the process of the breaking of drops put forward by Simpson ${ }^{4}$, which is recognized as responsible for the positive charge in the base of the thundercloud ; and there is the 'influence' process suggested by Wilson ${ }^{5}$ and verified in laboratory experiments by Gott ${ }^{6}$.

The breaking-drop process leaves a negative charge in the air, and this will give rise to the negative potential gradient directly. On the other hand, if the influence process gives a positive charge to the drops, there must first be a negative potential gradient below the cloud, due to a negative charge in the base of the cloud. If, within the cloud, there is the same process of ice-friction which operates in the thunder-cloud, this will give the requisite negative potential gradient.

The two processes which could give rise to the charges on raindrops are sharply distinguished in regard to the origin of the charges in the cloud and the consequent negative potential gradient. The breaking-drop process will, in itself, give rise to a negative charge in the cloud, and there will be no need for any positive charge to be assumed in the cloud. On the other hand, the influence process requires a 'bipolar' cloud, with negative charge below.

In the breaking-drop theory, the primary result of the process is the positive rain, the negative potential gradient being a consequence of this; whereas 